\title{
Early life opportunities for prevention of diabetes in low and middle income countries
}

Mark A Hanson', Peter D Gluckman ${ }^{2,3}$, Ronald CW Ma ${ }^{4,5}$, Priya Matzen ${ }^{6}$ and Regien G Biesma ${ }^{1,7^{*}}$

\begin{abstract}
Background: The global burden of diabetes and other non-communicable diseases is rising dramatically worldwide and is causing a double poor health burden in low- and middle-income countries. Early life influences play an important part in this scenario because maternal lifestyle and conditions such as gestational diabetes and obesity affect the risk of diabetes in the next generation. This indicates important periods during the lifecourse when interventions could have powerful affects in reducing incidence of non-communicable diseases. However, interventions to promote diet and lifestyle in prospective parents before conception have not received sufficient attention, especially in low- and middle-income countries undergoing socio-economic transition.
\end{abstract}

Discussion: Interventions to produce weight loss in adults or to reduce weight gain in pregnancy have had limited success and might be too late to produce the largest effects on the health of the child and his/her later risk of non-communicable diseases. A very important factor in the prevention of the developmental component of diabetes risk is the physiological state in which the parents enter pregnancy. We argue that the most promising strategy to improve prospective parents' body composition and lifestyle is the promotion of health literacy in adolescents. Multiple but integrated forms of community-based interventions that focus on nutrition, physical activity, family planning, breastfeeding and infant feeding practices are needed. They need to address the wider social economic context in which adolescents live and to be linked with existing public health programmes in sexual and reproductive health and maternal and child health initiatives.

Summary: Interventions aimed at ensuring a healthy body composition, diet and lifestyle before pregnancy offer a most effective solution in many settings, especially in low- and middle-income countries undergoing socio-economic transition. Preparing a mother, her partner and her future child for "the 1000 days", whether from planned or unplanned conception would break the cycle of risk and demonstrate benefit in the shortest possible time. Such interventions will be particularly important in adolescents and young women in disadvantaged groups and can improve the physiological status of the fetus as well as reduce the prevalence of pregnancy conditions such as gestational diabetes mellitus which both predispose to non-communicables diseases in both the mother and her child. Pre-conception interventions require equipping prospective parents with the necessary knowledge and skills to make healthy lifestyle choices for themselves and their children. Addressing the promotion of such health literacy in parents-to-be in low- and middle-income countries requires a wider social perspective. It requires a range of multisectoral agencies to work together and could be linked to the issues of women's empowerment, to reproductive health, to communicable disease prevention and to the Millennium Development Goals 4 and 5.

Keywords: Adolescents, Diabetes, Health literacy, Interventions, Life-course, Non-communicable diseases, Gestational diabetes mellitus, Obesity

\footnotetext{
* Correspondence: Rbiesma@rcsi.ie

${ }^{1}$ Institute of Developmental Sciences, Faculty of Medicine, University of

Southampton, Mailpoint 887, Southampton General Hospital, Tremona Road,

Southampton SO16 6YD, UK

${ }^{7}$ Department of Epidemiology and Public Health Medicine, Royal College of

Surgeons in Ireland, 123 St Stephens Green, Dublin 2, Ireland

Full list of author information is available at the end of the article
} 


\section{Background}

The rising incidence of diabetes in both developed and developing countries [1-3] is generating a large humanitarian and financial burden [4]. For example, at least 93 million people are affected by diabetes in China alone [5]. Especially worrying is the generalized fall in the age at onset of diabetes $[2,6]$. With rapidly increasing globalization, lifestyles in low- and middle-income countries (LMICs) increasingly include high fat and caloriedense diets and inadequate physical exercise and are resulting in an increased worldwide burden of NonCommunicable Diseases (NCDs) [7]. LMICs thus now face a double burden - continued high rates of infectious diseases and rapidly growing NCD prevalence. Globally, $85 \%$ of all people with undiagnosed diabetes are in LMICs, where resources are often lacking and governments may not prioritize screening for the condition [3]. In addition, the interaction between diabetes and major infectious diseases has a large impact on public health within developing countries (such as in Sub-Saharan Africa) and adversely affects progress towards the Millennium Development Goals (MDGs) [8-10]. Poverty, inequality, lack of education and the nature of the nutritional transition are root causes of the problem [11] while limited resources mean that NCDs must compete for political attention and financial investment [10]. Following several recent regional and international meetings and initiatives [12] including the UN high-level meeting on prevention and treatment of NCDs from 19-20 September 2011 [13], the global threat of diabetes and other NCDs is beginning to receive greater political attention. Until recently, there was much publicity for the view that diabetes and NCDs were largely manifest in adults as a result of the biblical sins of 'gluttony and sloth', so there was both an urgent need to get individuals to take more responsibility for their adult lifestyle and to discourage the food industry from producing the 'unhealthy' foods which fuelled this epidemic of disease [8]. However, a substantial body of evidence makes it clear that early life influences also play an important part here, and that maternal (and, to a degree, paternal) lifestyle and conditions such as gestational diabetes affect not only prenatal and infant development but also the adequacy of responses to later challenges such as an obesogenic lifestyle. This emphasises the importance of NCD risk reduction starting in adolescents and young women before conception and during pregnancy [14].

In this review, we examine the role of early life influences on diabetes risk, and argue that interventions to promote diet and lifestyle in prospective parents before conception have not received sufficient attention, especially in LMICs undergoing socio-economic transition. Such interventions will be particularly important in adolescents and young women and seem likely not only to reduce the prevalence of NCDs in the next generation but also to reduce that of pregnancy conditions such as gestational diabetes mellitus (GDM), which predispose to NCDs in both the mother and her child. We therefore propose that greater emphasis on promotion of health literacy, coupled with screening for risk and management of chronic health conditions such as obesity and diabetes, prior to conception will be an important additional approach to tackling the epidemic of NCDs. If effective, this may be a cost-effective way of addressing the epidemic of NCDs such as diabetes.

\section{Discussion}

\section{Early life influences on diabetes risk}

We have argued that diabetes incidence is rising so fast in young people in LMICs not solely because of the adoption of attributes of Western lifestyle, but also because the evolved biology of human early life has not prepared individuals for such a challenge - the mismatch hypothesis [14]. The operation of maternal constraint $[15,16]$, by which processes operate to match the growth of the fetus to maternal body proportions such as pelvic dimensions, occurs in all pregnancies, and thus makes each of us potentially mismatched to our postnatal environment. However, the degree of this mismatch varies. The processes of maternal constraint, and thus the risk of later mismatch, appear to operate more powerfully in teenage pregnancies and in primipara. Thus interventions targeted to this time in the mother's lifecourse may be particularly effective in reducing NCD risk in the next generation.

A body of knowledge is accumulating which suggests that environmental factors act in early life via epigenetic factors to set the development of many aspects of the offspring phenotype, contributing to potential later mismatch [17]. This model (see Figure 1) posits that critical components of risk are established early in development, when information about the current environment affects the settings of homeostatic control processes influencing the individual's responses to their later environment: the underlying mechanisms involve the evolutionary conserved processes of developmental plasticity $[17,18]$. Central to developmental plasticity is the concept that the mother is able to pass on information about the external environment during pregnancy and nursing of her infant. The level and fidelity of these processes is influenced by a wide range of factors including mother's genetic makeup, her early life, her current nutritional status, age, body composition and proportions, lifestyle (especially level of physical activity, smoking, alcohol consumption), parity and external stressors such as infection, pollution etc. [19]. Hence aspects of maternal phenotype and trans-generational environmental changes can lead to increased risk of disease in the offspring when 


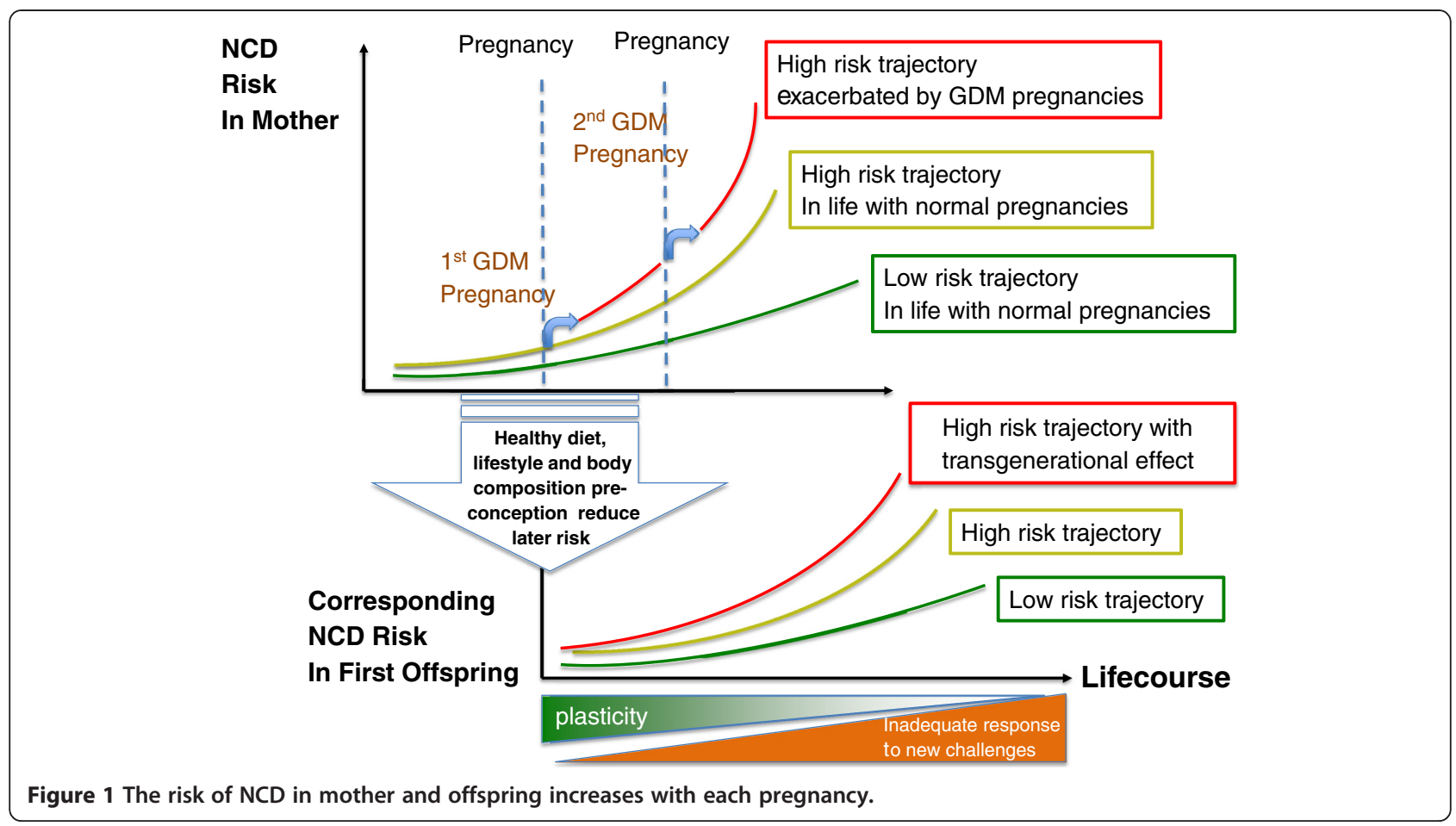

what has been promised about the environment, 'inferred' from intrauterine or neonatal cues, turns out not to be accurate. Such a mismatch between the biology induced during prenatal life and later environment has been suggested to increase the risk of NCDs being passed from one generation to the next; it is supported by extensive experimental and clinical data $[17,20]$.

The risk of NCD such as diabetes is present in everyone and increases throughout the lifecourse. In women the insulin resistance of pregnancy increases such risk (upward excursions shown here for two pregnancies), particularly of GDM but also of type 2 diabetes and cardiovascular disease. This contributes to transmission of NCD risk to the next generation. Early development affects the trajectory of this risk, thus a focus on health before conception reduces NCD risk in both the mother and her children (based on Godfrey et al., 2010 [19] and Sattar and Greer, 2002 [43].

\section{Diabetes begetting diabetes and the role of gestational diabetes and maternal obesity}

The processes noted above do not constitute the only developmental pathway leading to intergenerational passage of risk of NCDs. It is alarming that an increasing number of women develop type 2 diabetes during their reproductive years [21,22]. Epidemiological studies show that children born to type 1 or 2 diabetic mothers also have a greater susceptibility to diabetes and obesity in later life [23,24]. That this risk is related to intra-uterine exposure to hyperglycaemia is shown by the observation that, among siblings, the risk of diabetes is higher in those born after the mother was diagnosed with diabetes [25]. These observations have been extended recently, as offspring exposed even to mild hyperglycaemia during pregnancy have increased adiposity and are at increased risk of later diabetes and cardiometabolic disease $[26,27]$. Through perpetuation of the cycle of 'diabetes begetting diabetes', these factors are driving further escalation of the epidemic of NCDs [28,29]. Recent animal data now also raise the possibility of paternal transmission of diabetes risk between generations [30] so the focus of potential interventions should not only be on women.

The rising prevalence of maternal obesity is of particular concern in populations undergoing rapid socioeconomic transitions $[1,2,21]$. Obesity is associated with an increased risk of many pregnancy complications such as hypertension, preeclampsia, and GDM. Evidence shows that a child of an obese mother may suffer from exposure to a suboptimal environment in utero and is also more likely to become obese $[31,32]$. Experimentally feeding pregnant animals a high fat diet gives rise to offspring who become overweight and who demonstrate a range of metabolic and functional disorders similar to the human metabolic syndrome and which have now been shown to be associated with epigenetic changes such as DNA methylation at components of genes involved in hepatocyte production and metabolism, [33]. 
Pregnancy represents a state of relative maternal insulin resistance, which helps promote the transfer of nutrients such as glucose, fatty acids and amino acids to the fetus [34]. Placental nutrient transfer is determined by the concentration gradient, blood flow and the operation of active and facilitated transporters [35]. However, in contrast to amino acids, there is no upper limit to placental transfer of glucose as maternal blood levels rise, suggesting that the rates of glucose exposure of the fetus that are often now experienced are novel in evolutionary terms. As a result, moderately increased fetal glucose supply will lead to fetal hyperinsulinaemia and a small increase in lean body as well as fat mass [36-39]. This may be viewed as adaptive as in the neonatal period relative adiposity provides metabolic reserves for thermogenesis and critical organ function in the event of inadequate maternal care [18]. GDM can be envisaged as the more extreme outcome of physiological processes, when maternal insulin resistance is accentuated by the woman's own developmental, genetic and environmental circumstances: for example, women of lower birth weight have a greater risk of developing GDM [37], whilst genetic variants associated with type 2 diabetes are also associated with increased risk of GDM [40,41]. In the evolutionary mismatched situation of overnutrition and low levels of physical activity, now increasingly common for women in their reproductive years, such mechanisms contribute not only to the rise in GDM but to that in obesity and diabetes in their children, and play an important role in perpetuating a vicious cycle of disease. For example, a recent paper shows that in Canadian first nation peoples up to $30 \%$ of the incidence of type 2 diabetes has its origin in GDM in the previous generation [42]. Conditions such as GDM carry risk of cardiovascular disease for both the mother as well as the child, a risk which increases with each pregnancy (Figure 1) [43]. These findings have significant long-term implications for global public health. Now more than ever, effective strategies for preventing GDM are needed.

\section{Current public health strategies in adults have limited success}

Most interventions to promote diet and lifestyle aimed at reducing overweight/ obesity, and thus the risk of NCDs such as diabetes later in life, have focused on adults. However, evidence suggests that interventions aimed at weight loss in adults or to prevent excessive weight gain during pregnancy and subsequent weight retention have had limited success. First, weight loss and persistent changes in lifestyle are difficult to sustain in adults because the neuroendocrine changes that drive appetite remain unaltered [44]. There is growing evidence of antenatal and infant determinants of appetite and food preference that persist through adult life [45-47]. Therefore relying on adult reversal of weight gain as a preventative approach is a flawed strategy in developed countries and is even more likely to be flawed in less developed societies. In addition, greater maternal pre-pregnancy weight and gestational weight gain up to 36 weeks of gestation are associated with greater offspring adiposity and adverse cardiovascular risk factors [48]. Finally, recent evidence shows that risk factors for diabetes and cardiovascular disease are no greater in non-obese adults who had been obese children than they are in individuals who had never been obese, but are clearly less than those in people who became obese as adults or who were obese both as children and adults [49]. This makes a strong case for focusing earlier in life before appetite control, food preference and fat cell number are established, and before obese children reach adulthood.

\section{Intervening from conception - the 1000 days}

There has been much publicity on the 1000 days campaign to improve nutrition of mothers and children in developing countries launched by the $1^{\text {st }}$ Lady of the USA (http://www.thousanddays.org/). This period of life covers a woman's pregnancy and the first 2 years of her child's postnatal life, a time when the processes of developmental plasticity operate powerfully to influence offspring phenotype and when excessive growth, as determined by crossing of more than 2 centiles is associated with later adiposity in childhood [50]. Despite a unique window of opportunity to shape the healthy future of mothers and children during this period, findings are inconsistent in relation to which factors need to be targeted in interventions to reduce the risk of later NCDs such as diabetes. First, even though evidence shows that preventing excessive gestational weight gain improves maternal, neonatal and pregnancy outcomes such as the risk of preeclampsia, preterm delivery and gestational diabetes [51-54], there is limited evidence of interventions to manage weight during this period being effective $[55,56]$. Poor intervention effectiveness seems to be related to inadequately addressing (social) barriers that women experience in achieving a healthy weight gain in pregnancy, such as a perceived lack of control and contradictory and conflicting messages about nurturing behaviours during pregnancy [56]. Pregnancy is a time of when many influences operate on parents and it may not be the best time for messages to be delivered about preventing excessive weight gain in women. Secondly, there is a growing body of evidence that breast feeding for at least 4 months leads to a reduction in long-term obesity in the child $[57,58]$ and that the introduction of solids before the age of 4 months both in formula- or breast-fed infants is associated with later obesity [59]. A recent study [60] suggests that selfweaned children are less likely to become obese, 
showing that relatively subtle changes in infant care may have long-term effects. Despite the overwhelming evidence that breastfeeding benefits mother and child, current breastfeeding rates worldwide are far from optimal, particularly among low-income, overweight and obese women [61,62]. Breastfeeding initiation and duration, and its exclusivity, are positively associated with the age, educational level and SES of the mother, while there is an inverse pattern for early formula and cow's milk consumption [62]. Again, a woman's ability to adhere to health recommendations (in this case to infant feeding practices) seems to be influenced by a wide range of socio-economic and cultural variables. In contrast to intervention to reduce excessive weight gain during pregnancy, treatment of mild gestational diabetes was associated with reduced risk of fetal overgrowth or adiposity at birth $[63,64]$.

There is some evidence that home-based early mentoring interventions, focusing on interpreting infants' cues, non-food methods of managing infant behavior, and mother-grandmother interactions are effective in improving infant feeding practices and delaying early complementary infant feeding among adolescent and low-income mothers $[65,66]$. This indicates that multiple types of interventions, including community based strategies such as educating young girls, the wider family and the social network, are needed to address this complex health problem, especially in disadvantaged groups.

\section{Potential early life interventions- intervening before conception is critical}

A very important factor in the prevention of the developmental component of diabetes risk is the physiological state in which the parents enter pregnancy - i.e. the diet, body composition and lifestyle of the mother and to a lesser extent the father. There is considerable data from experimental studies in a range of animal species and prospective studies in humans that the mother's diet and body composition before and in early pregnancy are related to phenotypic characteristics of the child, such as adiposity at birth and in childhood, and markers of cardiovascular risk such as carotid artery intima-media thickness [67-69]. The processes involved in influencing embryonic and fetal development are gradually being unravelled. Both animal and human studies reveal effects on placental function [70], the development of fetal organ function and on epigenetic processes in the offspring early in development [71]. Most couples will not be aware that they have conceived until after about 6-8 weeks of pregnancy, especially in societies where a high proportion of pregnancies are unplanned. Lower SES women tend to link with health care professionals later in pregnancy. Thus interventions in mid-late pregnancy will be too late to produce the largest effects on the health of the child and his/her later risk of NCDs. Moreover teenage pregnancy occurs at a time when the girl is still growing: resources are allocated to this growth rather than to her fetus, further compromising its development. In recently conducted research in the UK, it is clear that maternal diabetes during pregnancy is accompanied by a greater risk of birth defects and complicated pregnancy outcomes [41]. Therefore it is important that women and their partners are screened for risk factors before they plan pregnancy to improve health outcomes for both the mother and offspring.

The relation between overweight/ obesity and NCD such as diabetes, is clearly not simple [72] and interventions need to be multifaceted and incorporated into social context. So far, very few interventions to reduce childhood obesity have been set up at the community level [73] and outside the school environment [74]. Community-based interventions are particularly important in societies where teenage girls who may be married at a very young age and become pregnant soon after, or who may have an unplanned pregnancy, and are more likely to cease attending school. We argue that focussing interventions on the adolescent girl, and her partner, necessitates promotion of health literacy, such as lifestyle, family planning and the importance of breastfeeding. Health literacy means more than being able to read pamphlets and successfully make appointments. By improving people's access to health information and their capacity to use it effectively, health literacy is critical to empowerment [75]. Health literacy in adolescents is more likely to be taken to the highest level of critical thinking about health and lifestyle if it is made context-specific and conducted outside the school environment, which is associated with authority and which may not be available to many girls in particular. Low health literacy affects the cognitive and social skills that determine the motivation and ability of women to gain access to, understand, and use information to engage in health promotion and prevention activities both for her and her (future) children [76-78]. Children of parents with higher literacy skills are more likely to have better outcomes in child health promotion and disease prevention [79]. It has been suggested that health education interventions that include clearly written education material that are appropriate for (future) parents' health knowledge with brief counselling would be an effective strategy to reduce health literacy-related disparities [76,77].

\section{Delivering pre-conception interventions in LMICS}

Delivering these interventions should be done carefully and after identifying the right channels. In many countries the existing public health programmes which focus on sexual and reproductive health may offer opportunities to deliver such interventions in a cost effective manner to adolescents and women of reproductive age. 
However, our experience [80] is that effective programmes may need to pay close attention to the pedagogical approach used which will have to be tailored to the community. It is important that measures of harm or unintended consequences are included in evaluations targeting eating and activity related behaviours in adolescents, where body image sensitivities are common and could possibly result in causing unintended consequences such as stigmatisation, low self-esteem or unhealthy dieting practices [81]. An additional challenge in trying to improve adolescents' nutrition or physical activity is that some cultures have less negative views on overweight individuals and a larger body type is accepted socio-culturally, or even found desirable as a sign of prosperity or being HIV negative. It will be critical to incorporate the positive elements of such culture regarding body image and food rather than attempting to shift values toward those of Western culture [82].

Four million neonatal deaths occur every year [83], many in LMICs, and there is universal concern that the goal of MDG-4 to promote child survival will not be met in most settings. Considerable reductions in this mortality, in a cost-effective manner, can be achieved by implementing an integrated programme combining outreach and family-community care with facility-based clinical services [84]. In our view it is important that emphasis on preventing maternal and neonatal mortality does not occur at the expense of adopting a longer-term lifecourse strategy, starting pre-conception [85], needed for NCD prevention. However it is pleasing to note that the Political Declaration at the High Level meeting on NCDs at the UN in Sept 2011 specifically recognised the important role of maternal and child health in NCD prevention (clause 26)[13].

Based on the evidence presented in this review, we believe that real opportunities exist for developing community-based family-lifestyle change interventions to improve access to and use of reliable information on NCDs and to promote a healthy lifestyle among adolescents and young women in LMICs. There is an urgent need to conduct research on pilot schemes tailored to this subgroup. These will need to be based in the community and relate to socio-economic factors $[84,85]$, be culturally appropriate and context specific and involve primary health care workers, schools, parents and caregivers and other social organisations. They may need to include simple health-monitoring or exercise tests and screening for blood glucose, for which the results can be used to monitor effectiveness and also fed back to participants to maintain motivation and self-efficacy [81]. Such programmes are perhaps best piloted in societies where there is a proven track-record in health promotion, e.g. through HIV-AIDS programmes, and where there is existing infrastructure to accelerate results.
Indeed, it will be important that such pilot schemes are integrated into, rather than compete with, other programmes in sexual health, drug, smoking and alcohol consumption reduction etc. Such a programme would then dovetail with antenatal health monitoring programmes, and with the early diagnosis and prevention of conditions such as GDM. For the latter, many of the first line intervention options such as diet, physical exercise and weight control are similar to the behaviours to be promoted in adolescents before conception. The programme would similarly link effectively with $\mathrm{MCH}$ initiatives aimed at reducing preterm- and stillbirth and maternal mortality and with postnatal healthcare programmes, aimed at promoting breast feeding, healthy supplementary and weaning foods, vaccination etc. The burden of NCDs impacts heavily on women's health and integrating NCD prevention and control into maternal and child health programmes will improve access to NCD services [86]. This approach requires an agenda broader than health agencies alone and it would be desirable that a broader range of global agencies such as UNDP, UNESCO, UNICEF, and UN Women became active alongside WHO [87].

\section{Discussion: seeing the bigger picture}

The long-term consequences of a poor start to life include greater risk of NCDs such as diabetes and cardiovascular disease as well as greater risks of childhood morbidity and mortality and impaired cognitive and emotional development. Just as cycles of disadvantage in one generation lead to disadvantage in the next, obesity, gestational diabetes, maternal ill health and under-nutrition can lead to health disparities and disease in the next generation. The perceived long time lag between instituting an intervention in early life and detecting a beneficial effect on NCD incidence in adults has inevitably reduced the sense of urgency in implementing such interventions, particularly in the context of short-term outcomes such as maternal or child mortality and communicable disease. However we are now in a position to use shorter-term intermediate outcome markers of later disease risk to monitor and promote a healthy start to life programmes such as those in pre-conception care. Such programmes might demonstrate: a reduction in cardio-metabolic risk factors in adolescents; reduced occurrence or severity of GDM; improvement in pregnancy outcomes such as macrosomia, dystocia and hypoglycaemia of the neonate. For such interventions the evidence base is strong. For other intermediate outcome markers, such as a healthier profile of epigenetic markers at birth in umbilical cord, placenta or cord blood, the evidence base is rapidly accumulating. Postnatally there are also opportunities to use outcome markers, for example trajectories of growth in the first two years [50], profiles of inflammatory and other 
biomarkers in children [88]; and incidence of some infant and early childhood disorders such as wheeze and asthma [89]. Clearly, the earlier and intervention is instituted, the more likely it is to be effective. There is thus an urgent need to conduct pre-conception interventions, to measure their efficacy and conduct cost-benefit analysis of this approach to NCD risk reduction.

\section{Abbreviations}

GDM: Gestational Diabetes Mellitus; GWG: Gestational Weight Gain; HIV/ AIDS: Human immunodeficiency virus/ Acquired immune deficiency syndrome; LMICs: Low and Middle Income Countries; MCH: Maternal and Child Health; NCD: Non-communicable Diseases; SES: Socioeconomic status; WHO: World Health Organization; UNDP: United Nations Development Program; UNESCO: United Nations Educational Scientific and Cultural Organization; UNICEF: United Nations Children's Fund.

\section{Competing interests}

PDG and MAH have received honoraria and travel costs/expenses for speaking at conferences sponsored by nutrition companies (Nestle, Danone, Abbott). Since 2010, RCWM has received speaker honoraria at academic meetings supported by Astra Zeneca, Boehringer-Ingelheim, Danone, Eli Lilly, Nestle and Pfizer. All proceeds have been donated to the Chinese University of Hong Kong to support diabetes research.

\section{Authors' contributions}

All authors participated in deciding content, reviewing evidence, and writing this review. All authors read and approved the final manuscript.

\section{Acknowledgements}

MAH is supported by the British Heart Foundation. PDG is supported by the National Research Centre for Growth and Development, NZ and the Singapore Institute for Clinical Sciences. RCWM acknowledges support from the Albert Renold Fellowship, the European Association for the Study of Diabetes, and the EFSD/CDS/Lilly Collaborative Research Programme from the European Association for the Study of Diabetes

\section{Author details \\ ${ }^{1}$ Institute of Developmental Sciences, Faculty of Medicine, University of Southampton, Mailpoint 887, Southampton General Hospital, Tremona Road, Southampton SO16 6YD, UK. ${ }^{2}$ Liggins Institute, University of Auckland, Auckland, Private Bag 92019, Auckland 1023, New Zealand. ${ }^{3}$ Singapore Institute of Clinical Sciences, Brenner Centre for Molecular Medicine, 30 Medical Drive, Singapore 117609, Singapore. ${ }^{4}$ Department of Medicine and Therapeutics, Chinese University of Hong Kong, Shatin, Hong Kong, SAR, China. ${ }^{5}$ Hong Kong Institute of Diabetes and Obesity, Chinese University of Hong Kong, Prince of Wales Hospital, Shatin, Hong Kong, SAR, China. ${ }^{6}$ Novo Nordisk A/S, Novo Allé, DK-2880, Bagsværd, Denmark. 'Department of Epidemiology and Public Health Medicine, Royal College of Surgeons in Ireland, 123 St Stephens Green, Dublin 2, Ireland.}

Received: 17 May 2012 Accepted: 12 November 2012 Published: 23 November 2012

\section{References}

1. Ramachandran A, Ma RC, Snehalatha C: Diabetes in Asia. Lancet 2010, 375(9712):408-418

2. Chan JC, Malik V, Jia W, Kadowaki T, Yajnik CS, Yoon KH, Hu FB: Diabetes in Asia: epidemiology, risk factors, and pathophysiology. JAMA 2009, 301(20):2129-2140.

3. Diabetes Atlas. http://www.idf.org/diabetesatlas/5e/undiagnosed-diabetes]

4. Narayan KM, Ali MK, Koplan JP: Global noncommunicable diseases-where worlds meet. N Eng J Med 2010, 363(13):1196-1198.

5. Yang W, Lu J, Weng J, Jia W, Ji L, Xiao J, Shan Z, Liu J, Tian H, Ji Q, et al: Prevalence of diabetes among men and women in China. $N$ Engl J Med 2010, 362(12):1090-1101.

6. Lawrence JM, Contreras R, Chen W, Sacks DA: Trends in the prevalence of preexisting diabetes and gestational diabetes mellitus among a racially/ ethnically diverse population of pregnant women, 1999-2005. Diabetes Care 2008, 31(5):899-904.

7. Maher D, Sekajugo J: Research on health transition in Africa: time for action. Health Research Policy \& Systems 2011, 9(1):5.

8. Beaglehole R, Bonita R, Alleyne G, Horton R, Li L, Lincoln P, Mbanya JC, McKee M, Moodie R, Nishtar S, et al: UN High-Level Meeting on NonCommunicable Diseases: addressing four questions. Lancet 2011, 378 (9789):449-455.

9. Young F, Critchley JA, Johnstone LK, Unwin NC: A review of co-morbidity between infectious and chronic disease in Sub Saharan Africa: TB and diabetes mellitus, HIV and metabolic syndrome, and the impact of globalization. Global Health 2009, 5:9.

10. Hall V, Thomsen RW, Henriksen O, Lohse N: Diabetes in Sub Saharan Africa 1999-2011: epidemiology and public health implications. A systematic review. BMC Public Health 2011, 11:564.

11. Stuckler D, Siegel K: Sick societies: responding to the global chakllenge of chronic disease. Oxford: Oxford University Press; 2011.

12. WHO: 2008-2013 Action Plan for the Global Strategy for the Prevention and Control of Noncommunicable Diseases. Geneva: WHO; 2008.

13. High Level meeting on Non-Communicable Diseases (NCD). http://www.who. int/nmh/events/un_ncd_summit2011/political_declaration_en.pdf.

14. Gluckman P, Hanson M: Mismatch. Why our world no longer fits our bodies. Oxford: Oxford University Press; 2006.

15. Gluckman PD, Hanson MA: Maternal constraint of fetal growth and its consequences. Semin Fetal Neonatal Med 2004, 9(5):419-425.

16. Godfrey KM, Lillycrop KA, Burdge GC, Gluckman PD, Hanson MA: Epigenetic mechanisms and the mismatch concept of the developmental origins of health and disease. Pediatr Res 2007, 61(5 Pt 2):5R-10R.

17. Gluckman PD, Hanson MA, Bateson P, Beedle AS, Law CM, Bhutta ZA, Anokhin KV, Bougneres P, Chandak GR, Dasgupta P, et al: Towards a new developmental synthesis: adaptive developmental plasticity and human disease. Lancet 2009, 373(9675):1654-1657.

18. Kuzawa CW: Fetal origins of developmental plasticity: are fetal cues reliable predictors of future nutritional environments? Am J Hum Biol 2005, 17(1):5-21.

19. Gluckman P, Beedle AS, Hanson M: Principles of Evolutionary Medicine. Oxford: Oxford University Press; 2009.

20. Godfrey KM, Gluckman PD, Hanson MA: Developmental origins of metabolic disease: life course and intergenerational perspectives. Trends Endocrinol Metab 2010, 21(4):199-205.

21. Ferrara A: Increasing prevalence of gestational diabetes mellitus: a public health perspective. Diabetes Care 2007, 30(Suppl 2):S141-S146.

22. Reece EA, Leguizamon G, Wiznitzer A: Gestational diabetes: the need for a common ground. Lancet 2009, 373(9677):1789-1797.

23. Poston L: Developmental programming and diabetes - The human experience and insight from animal models. Best Pract Res Clin Endocrinol Metab 2010, 24(4):541-552

24. Simeoni U, Barker DJ: Offspring of diabetic pregnancy: long-term outcomes. Semin Fetal Neonatal Med 2009, 14(2):119-124.

25. Dabelea D, Hanson RL, Lindsay RS, Pettitt DJ, Imperatore G, Gabir MM, Roumain J, Bennett PH, Knowler WC: Intrauterine exposure to diabetes conveys risks for type 2 diabetes and obesity: a study of discordant sibships. Diabetes 2000, 49(12):2208-2211.

26. Hyperglycemia and Adverse Pregnancy Outcome (HAPO) Study: associations with neonatal anthropometrics. Diabetes 2009, 58(2):453-459.

27. Tam WH, Ma RC, Yang X, Li AM, Ko GT, Kong AP, Lao TT, Chan MH, Lam CW, Chan JC: Glucose intolerance and cardiometabolic risk in adolescents exposed to maternal gestational diabetes: a 15-year follow-up study. Diabetes Care 2010, 33(6):1382-1384.

28. Ma RC, Chan JC: Pregnancy and diabetes scenario around the world: China. In International journal of gynaecology and obstetrics: the official organ of the International Federation of Gynaecology and Obstetrics.; 2009.

29. Yajnik CS: Fetal programming of diabetes: still so much to learn! Diabetes Care 2010, 33(5):1146-1148.

30. Freinkel N: Banting Lecture 1980, Of pregnancy and progeny. Diabetes 1980, 29(12):1023-1035.

31. Whitaker RC: Predicting preschooler obesity at birth: the role of maternal obesity in early pregnancy. Pediatrics 2004, 114(1):e29-e36.

32. Catalano PM, Ehrenberg HM: The short- and long-term implications of maternal obesity on the mother and her offspring. BJOG 2006, 113(10):1126-1133. 
33. Dudley KJ, Sloboda DM, Connor KL, Beltrand J, Vickers MH: Offspring of mothers fed a high fat diet display hepatic cell cycle inhibition and associated changes in gene expression and DNA methylation. PLoS One 2011, 6(7):e21662.

34. Lain KY, Catalano PM: Metabolic changes in pregnancy. Clin Obstet Gynecol 2007, 50(4):938-948.

35. Illsley NP: Glucose transporters in the human placenta. Placenta 2000, 21(1):14-22.

36. Wells JC: The thrifty phenotype as an adaptive maternal effect. Biol Rev Camb Philos Soc 2007, 82(1):143-172.

37. Egeland GM, Skjaerven R, Irgens LM: Birth characteristics of women who develop gestational diabetes: population based study. BMJ 2000, 321 (7260):546-547.

38. Susa JB, Schwartz R: Effects of hyperinsulinemia in the primate fetus. Diabetes 1985, 34(Suppl 2):36-41.

39. de Santis MS, Taricco E, Radaelli T, Spada E, Rigano S, Ferrazzi E, Milani S, Cetin I: Growth of fetal lean mass and fetal fat mass in gestational diabetes. Ultrasound Obstet Gynecol 2010, 36(3):328-337.

40. Lauenborg J, Grarup N, Damm P, Borch-Johnsen K, Jorgensen T, Pedersen O, Hansen T: Common type 2 diabetes risk gene variants associate with gestational diabetes. J Clin Endocrinol Metab 2009, 94(1):145-150.

41. Konig M, Shuldiner AR: The genetic interface between gestational diabetes and type 2 diabetes. J Matern Fetal Neonatal Med 2011, 25(1):36-40.

42. Dowse GK, Zimmet PZ, Finch CF, Collins VR: Decline in incidence of epidemic glucose intolerance in Nauruans: implications for the "thrifty genotype". Am J Epidemiol 1991, 133(11):1093-1104.

43. Sattar N, Greer IA: Pregnancy complications and maternal cardiovascular risk: opportunities for intervention and screening? BMJ 2002, 325(7356):157-160.

44. Sumithran P, Prendergast LA, Delbridge E, Purcell K, Shulkes A, Kriketos A, Proietto J: Long-term persistence of hormonal adaptations to weight loss. N Engl J Med 2011, 365(17):1597-1604.

45. Bachmanov AA, Inoue M, Ji H, Murata Y, Tordoff MG, Beauchamp GK Glutamate taste and appetite in laboratory mice: physiologic and genetic analyses. Am J Clin Nutr 2009, 90(3):756S-763S.

46. Beauchamp GK, Moran M: Dietary experience and sweet taste preference in human infants. Appetite 1982, 3(2):139-152.

47. Beauchamp GK, Moran M: Acceptance of sweet and salty tastes in 2-year-old children. Appetite 1984, 5(4):291-305.

48. Fraser A, Tilling K, Macdonald-Wallis C, Sattar N, Brion MJ, Benfield L, Ness A, Deanfield J, Hingorani A, Nelson SM, et al: Association of maternal weight gain in pregnancy with offspring obesity and metabolic and vascular traits in childhood. Circulation 2010, 121(23):2557-2564.

49. Juonala M, Magnussen CG, Berenson GS, Venn A, Burns TL, Sabin MA, Srinivasan SR, Daniels SR, Davis PH, Chen W, et al: Childhood adiposity, adult adiposity, and cardiovascular risk factors. N Engl J Med 2011, 365(20):1876-1885.

50. Taveras EM, Rifas-Shiman SL, Sherry B, Oken E, Haines J, Kleinman K, RichEdwards JW, Gillman MW: Crossing growth percentiles in infancy and risk of obesity in childhood. Arch Pediatr Adolesc Med 2011, 165(11):993-998.

51. Ray JG, Vermeulen MJ, Shapiro JL, Kenshole AB: Maternal and neonatal outcomes in pregestational and gestational diabetes mellitus, and the influence of maternal obesity and weight gain: the DEPOSIT study, Diabetes Endocrine Pregnancy Outcome Study in Toronto. QJM 2001, 94(7):347-356

52. Cedergren M: Effects of gestational weight gain and body mass index on obstetric outcome in Sweden. International journal of gynaecology and obstetrics: the official organ of the International Federation of Gynaecology and Obstetrics 2006, 93(3):269-274.

53. Siega-Riz AM, Viswanathan M, Moos MK, Deierlein A, Mumford S, Knaack J, Thieda P, Lux LJ, Lohr KN: A systematic review of outcomes of maternal weight gain according to the Institute of Medicine recommendations: birthweight, fetal growth, and postpartum weight retention. Am J Obstet Gynecol 2009, 201(4):e331-314. 339.

54. Hedderson MM, Weiss NS, Sacks DA, Pettitt DJ, Selby JV, Quesenberry CP, Ferrara A: Pregnancy weight gain and risk of neonatal complications: macrosomia, hypoglycemia, and hyperbilirubinemia. Obstet Gynecol 2006, 108(5):1153-1161.

55. Tanentsapf I, Heitmann BL, Adegboye AR: Systematic review of clinical trials on dietary interventions to prevent excessive weight gain during pregnancy among normal weight, overweight and obese women. BMC Pregnancy Childbirth 2011, 11:81.

56. Campbell F, JOhnson M, Messina J, Guillaume L, Goyder E: Behavioural interventions for weight management in pregnancy: a systematic review of quantitative and qualitative data. BMC Public Health 2011, 11(491):1-13.

57. Arenz S, Ruckerl R, Koletzko B, von Kries R: Breast-feeding and childhood obesity-a systematic review. Int J Obes Relat Metab Disord 2004, 28 (10):1247-1256.

58. Mayer-Davis EJ, Rifas-Shiman SL, Zhou L, Hu FB, Colditz GA, Gillman MW: Breast-feeding and risk for childhood obesity: does maternal diabetes or obesity status matter? Diabetes Care 2006, 29(10):2231-2237.

59. Huh SY, Rifas-Shiman SL, Taveras EM, Oken E, Gillman MW: Timing of solid food introduction and risk of obesity in preschool-aged children. Pediatrics 2011, 127(3):e544-e551.

60. Townsend E, Pitchford NJ: Baby knows best? The impact of weaning style on food preferences and body mass index in early childhood in a casecontrolled sample. BMJ Open 2012, 2(1):e000298.

61. Guttman N, Zimmerman DR: Low-income mothers' view on breastfeeding. Soc Sci Med 2000, 50:1457-1473.

62. Amir LH, Donath S: A systematic review of maternal obesity and breastfeeding intention, initiation and duration. BMC Pregnancy Childbirth 2007, 7:9.

63. Landon MB, Spong CY, Thom E, Carpenter MW, Ramin SM, Casey B, Wapner RJ, Varner MW, Rouse DJ, Thorp JM Jr, et al: A multicenter, randomized trial of treatment for mild gestational diabetes. N Engl J Med 2009, 361(14):1339-1348.

64. Gillman MW, Oakey H, Baghurst PA, Volkmer RE, Robinson JS, Crowther CA: Effect of treatment of gestational diabetes mellitus on obesity in the next generation. Diabetes Care 2010, 33(5):964-968.

65. Wen LM, Baur LA, Simpson JM, Rissel C, Flood VM: Effectiveness of an early intervention on infant feeding practices and "tummy time": a randomized controlled trial. Arch Pediatr Adolesc Med 2011, 165(8):701-707.

66. Black MM, Bentley ME, Papas MA, Oberlander S, Teti LO, McNary S, Le K, O'Connell M: Delaying second births among adolescent mothers: a randomized, controlled trial of a home-based mentoring program. Pediatrics 2006, 118(4):e1087-e1099.

67. Symonds ME, Sebert SP, Hyatt MA, Budge H: Nutritional programming of the metabolic syndrome. Nat Rev Endocrinol 2009, 5(11):604-610.

68. Gale CR, Jiang B, Robinson SM, Godfrey KM, Law CM, Martyn CN: Maternal diet during pregnancy and carotid intima-media thickness in children. Arterioscler Thromb Vasc Biol 2006, 26(8):1877-1882.

69. Sebayang SK, Dibley MJ, Kelly P, Shankar AV, Shankar AH: Modifying effect of maternal nutritional status on the impact of maternal multiple micronutrient supplementation on birthweight in Indonesia. Eur J Clin Nutr 2011, 65(10):1110-1117.

70. Lewis RM, Cleal JK, Hanson MA: Review: Placenta, evolution and lifelong health. Placenta 2012, 33:S28-S32.

71. Lillycrop KA, Rodford J, Garratt ES, Slater-Jefferies JL, Godfrey KM, Gluckman PD, Hanson MA, Burdge GC: Maternal protein restriction with or without folic acid supplementation during pregnancy alters the hepatic transcriptome in adult male rats. Br J Nutr 2010, 103(12):1711-1719.

72. Gluckman P, Hanson M: Fat, fate and disease. New York: Oxford University Press; 2012.

73. Janicke DM, Lim CS, Perri MG, Bobroff LB, Mathews AE, Brumback BA, Dumont-Driscoll M, Silverstein JH: The Extension Family Lifestyle Intervention Project (E-FLIP for Kids): design and methods. Contemp Clin Trials 2011, 32(1):50-58

74. Waters E, Armstrong R, Swinburn B, Moore L, Dobbins M, Anderson L, Petticrew M, Clark R, Conning R, Moodie M, et al: An exploratory cluster randomised controlled trial of knowledge translation strategies to support evidence-informed decision-making in local governments (The KT4LG study). BMC Public Health 2011, 11:34.

75. Nutbeam D: Health literacy as a public health goal: a challenge for contemporary health education and communication strategies into the 21st century. Health Promot Int 2000, 15(3):259-267.

76. Shieh C, Halstead JA: Understanding the impact of health literacy on women's health. Obstet Gynecol Neonatal Nurs 2009, 38(5):601-610. quiz 610-602.

77. DeWalt DA, Hink A: Health literacy and child health outcomes: a systematic review of the literature. Pediatrics 2009, 124(Suppl 3):S265-274.

78. Renkert S, Nutbeam D: Opportunities to improve maternal health literacy through antenatal education: an exploratory study. Health Promot Int 2001, 16(4):381-388. 
79. Sanders LM, Shaw JS, Guez G, Baur C, Rudd R: Health literacy and child health promotion: implications for research, clinical care, and public policy. Pediatrics 2009, 124(Suppl 3):S306-314.

80. Bay JL, Mora HA, Sloboda DM, Vickers MH, Cooper S, PD. G: Exploring the Potential of School Based Adolescent Intervention To Enable Translation of DOHaD Concepts into Community Understanding. Journal of Developmental Origins of Health and Disease 2011, 2(1):O-23i-23. S26.

81. Waters E, de Silva-Sanigorski A, Hall BJ, Brown T, Campbell KJ, Gao Y, Armstrong R, Prosser L, Summerbell CD: Interventions for preventing obesity in children. Cochrane Database Syst Rev 2011, 12:CD001871.

82. Baskin ML, Ahluwalia HK, Resnicow K: Obesity intervention among African-American children and adolescents. Pediatr Clin North Am 2001, 48(4):1027-1039

83. Lawn JE, Cousens S, Bhutta ZA, Darmstadt GL, Martines J, Paul V, Knippenberg R, Fogstadt H, Shetty P, Horton R: Why are 4 million newborn babies dying each year? Lancet 2004, 364(9432):399-401.

84. Darmstadt GL, Bhutta ZA, Cousens S, Adam T, Walker N, de Bernis L: Evidence-based, cost-effective interventions: how many newborn babies can we save? Lancet 2005, 365(9463):977-988.

85. Atrash H, Jack BW, Johnson K, Coonrod DV, Moos MK, Stubblefield PG, Cefalo R, Damus K, Reddy UM: Where is the "W"oman in $\mathrm{MCH}$ ? Am J Obstet Gynecol 2008, 199(6 Suppl 2):S259-265.

86. Maina WK: Integrating noncommunicable disease prevention into maternal and child health programs: can it be done and what will it take? International journal of gynaecology and obstetrics: the official organ of the International Federation of Gynaecology and Obstetrics 2011. 115(Suppl 1):S34-36.

87. Gluckman PD, Hanson M, Zimmet P, Forrester T: Losing the war against obesity: the need for a developmental perspective. Sci Trans/ Med 2011, 3(93): $93 \mathrm{~cm} 19$.

88. Martinez JA, Cordero P, Campion J, Milagro FI: Interplay of early-life nutritional programming on obesity, inflammation and epigenetic outcomes. Proc Nutr Soc 2012, 71(2):276-283.

89. Yang KD: Perinatal programming of childhood asthma. Clin Dev Immunol 2012, 2012:438572.

doi:10.1186/1471-2458-12-1025

Cite this article as: Hanson et al:: Early life opportunities for prevention of diabetes in low and middle income countries. BMC Public Health 2012 12:1025.

\section{Submit your next manuscript to BioMed Central and take full advantage of:}

- Convenient online submission

- Thorough peer review

- No space constraints or color figure charges

- Immediate publication on acceptance

- Inclusion in PubMed, CAS, Scopus and Google Scholar

- Research which is freely available for redistribution 